\title{
Rancangan Pemberdayaan Masyarakat Pada Pengelolaan Hutan Kemasyarakatan (HKm) Desa Pacekke, Kecamatan Soppeng Riaja, Kabupaten Barru, Sulawesi Selatan
}

\author{
Nur Awaliyah Reski', Yusran Yusran², Makkarennu2,** \\ ${ }^{1}$ Mahasiswa Fakultas Kehutanan Universitas Hasanuddin, Makassar \\ ${ }^{2}$ Staf Pengajar Fakultas Kehutanan Universitas Hasanuddin \\ *E-mail: makkarennu@unhas.ac.id
}

\begin{abstract}
The aim of this study are identified needs to improvecommunity capacity and develop community empowerment plan. This study was used interview method, observation, and references. Selection of samples is done by purposive sampling with community criteria incorporated in Forest Farmer Group of MegahBuana and identified the needs of community capacity building through five strategic issues. The five issues i.e.policy, institutional, forest resources, human resources, economy and social.In the final stages community empowerment plan is made where they were in and around forest for minimalize effect of the consequences of these five strategic issues. The results shown that policy issues, there are limited access to forest resources and high public dependence on government programs. So it needs community empowerment policy where it's transparent, participatory, consistent and targeted to community. In the institutional issues there are poorof public access to capital, markets, science and technology, and the bargaining position of communities in low partnerships, it is necessary to develop institutional capacity based on institutional-based institutional. In the forest resource issues, forest destruction thatincrease, so it is necessary to design community-based forest resources. In the human resources is less of ability from government officer as facilitator of empowerment, so it needs training plans of capacity building and competence of human resource by government apparatus.In theeconomy and social issues, there are less motivated to entrepreneurship because of the lack of available capital and economic infrastructure and the income of the community is still relatively low, so that need to develop improving access plan and strengthening socio-economic community.
\end{abstract}

Keywords: capacity improvement; community; community forest; forest; policy

DOl: http://dx.doi.org/10.24259/jhm.v9i1.2039

\section{PENDAHULUAN}

Pembangunan kehutanan dengan pola HKm harus lebih menitikberatkan pada upaya pemberdayaan untuk meningkatkan kapasitas masyarakat di dalam dan sekitar hutan. Hal ini disebabkan masyarakat desa yang hidup dan bertempat tinggal sejak lama di dalam dan di sekitar hutan mempunyai hubungan interaksi dan ketergantungan yang sangat erat dengan hutan serta sumberdaya yang ada di dalamnya, termasuk aspek kehidupan sosial budaya, ekonomi dan bahkan aspek religius (Harlen, 2010).

Memberdayakan masyarakat adalah upaya untuk meningkatkan peran serta masyarakat dan kemandirian melalui pendekatan partisipatif sehingga masyarakat memiliki ruang terbuka untuk mengembangkan potensi kreasi, mengontrol lingkungan dan sumberdayanya sendiri (Purnomo, 2013). Sedangkan menurut Noor (2011) dalam rangka untuk memberdayakan masyarakat dapat dikaji dari tiga aspek yaitu: (a). Enabling, menciptakan suasana yang memungkinkan potensi masyarakat dapat berkembang; (b). empowering, memperkuat potensi yang dimiliki masyarakat dalam berbagai peluang yang akan membuat masyarakat semakin berdaya; (c). Protecting, melindungi dan membela kepentingan masyarakat lemah

Kementerian Kehutanan (2007) menyatakan bahwa terdapat beberapa masalah yang perlu diperhatikan untuk penyelenggaraan pembangunan kehutanan khususnya kegiatan yang berkaitan dengan pemberdayaan di dalam dan sekitar hutan. Masalah tersebut yaitu dari isu kebijakan, isu kelembagaan, isu sumberdaya hutan, isu sumberdaya manusia dan isu sosial ekonomi. Kelima isu tersebut akan memunculkan berbagai dampak dimasa yang akan datang apabila tidak diminimalisir, untuk itu perlu adanya penyusunan rancangan pemberdayaan masyarakat yang sesuai dengan realitas kondisi saat ini . 
Penelitian ini menekankan pada penyusunan rancangan program pemberdayaan masyarakat yang mengacu kepada kebutuhan peningkatan kapasitas masyarakat. Penelitian ini dipandang perlu dilakukan karena fakta bahwa adanya kegagalan berbagai program dan proyek pemberdayaan perlu dianalisis dan sebagai pembelajaran untuk pengelolaan sektor kehutanan yang lebih baik. Pemilihan lokasi penelitian akan dilaksanakan di Desa Pacekke, Kecamatan Soppeng Riaja, Kabupaten Barru dengan dasar pertimbangan Desa tersebut telah diberikan Izin Usaha Pemanfaatan Hutan Kemasyarakatan (IUPHKm) sesuai pada Surat Keputusan Nomor: 1/L.13.P/P2.T/11/2016 dengan status kawasan hutan lindung yang sampai saat ini belum terdapat program terkait pemberdayaan masyarakat.

\section{METODE PENELITIAN}

Penelitian ini dilaksanakan pada bulan September 2016 hingga bulan April 2017, di Desa Pacekke Kecamatan Soppeng Riaja Kabupaten Barru.

Data yang diperlukan dalam penelitian ini adalah data primer dan data sekunder. Data primer adalah data yang diperoleh melalui wawancara mendalam, sedangkan data sekunder adalah data yang diperoleh dari laporan hasil penelitian, literatur, data-data dari instansi yang terkait serta data keadaan umum lokasi penelitian dan keadaan sosial ekonomi penduduk.

Analisis data yang digunakan adalah analisis deskriptif kualitatif dengan rincian kondisi sekarang dan konsekuensi dari kelima isu strategis. Pada tahap akhir dibuat skenario rancangan pemberdayaan masyarakat di dalam dan sekitar hutan.

\section{HASIL DAN PEMBAHASAN}

\subsection{Kebutuhan Peningkatan Kapasitas Masyarakat}

Hasil observasi dan wawancara dengan sejumlah responden diketahui bahwa terdapat beberapa masalah yang perlu dikaji dalam peningkatan kapasitas masyarakat pada Desa Pacekke yang diuraikan sebagai berikut :

1. Kebijakan, terdapat dua isu yang berkaitan dengan pemberdayaan masyarakat di dalam dan sekitar hutan yaitu: (a) masyarakat Desa Pacekke saat ini hanya mengelola hasil hutan berupa Kemiri dari $\mathrm{HKm}$ tersebut $\mathrm{Hal}$ ini disebabkan karena pemerintah masih kurang memperhatikan apa yang masyarakat sekitar HKm Pacekke butuhkan sehingga akses masyarakat terhadap manfaat potensi sumberdaya hutan kurang optimal dan merasa tidak memiliki sumberdaya hutan;(b)ketergantungan masyarakat terhadap program pemerintah dan pihak lainnya sangat tinggi sehingga inisiatif dan inovasi masyarakat tergolong rendah, masyarakat menjadi pasif serta tidak mandiri khususnya pada proses pengambilan keputusan.

2. Kelembagaan, terdapat dua isu yang berkaitan dengan pemberdayaan masyarakat di dalam dan sekitar hutan yaitu: (a) akses masyarakat terhadap modal, pasar, iptek dan dalam proses pengambilan kebijakan sangat minim sehingga masyarakat masih dalam kondisi marginal, apatis dan susah untuk mengembangkan unit usaha; (b)lemahnya posisi tawar masyarakat dalam kemitraan pengelolan sumberdaya hutan sehingga menyebabkan masyarakat (hampir) selalu dirugikan dan termarginalkan karena kemitraan memiliki prinsip kesetaraan dan saling menguntungkan. Apabila hal ini tidak terminimalisir maka akan menurunkan semangat dan mengurangi kreativitas masyarakat.

3. Sumberdaya Hutan, terdapat tiga isu yang berkaitan dengan pemberdayaan masyarakat di dalam dan sekitar hutan yaitu: (a) tingkat kerusakan hutan semakin meningkat akibat belum adanya kepastian program pada pengelolaan HKm di Pacekke, sehingga masyarakat hanya memanfaatkan Kemiri. Pohon Kemiri pada Lokasi HKm di Pacekke pun termasuk pohon sudah berumur tua yang telah lama ditanam oleh nenek moyang mereka sehingga kuantitas, kualitas dan kontiniutas dari produktivitas pohon Kemiri semakin menurun; (b) kurangnya manfaat sumberdaya hutan kepada masyarakat sehingga tidak ada peningktan kesejahteraan masyarakat dan masyarakat akan mencari alternatif usaha. Data dan informasi yang diperoleh dilapangan membuktikan bahwa masyarakat lebih menekuni pekerjaan seperti bertani dan beternak karena dapat memberikan income menguntungkan; (c)masyarakat kurang terlibat dalam pengelolaan pelestarian hutan karena memiliki pekerjaan lain yang lebih banyak menghasilkan nilai ekonomi. Akibat kurang terlibatnya masyarakat dalam 
pengelolaan HKm di Pacekke maka potensi sumberdaya hutan tidak dapat dimanfaatkan secara optimal.

4. Sumberdaya Manusia, terdapat dua isu yang berkaitan dengan pemberdayaan masyarakat di dalam dan sekitar hutan yaitu: (a) Hasil yang diperoleh melalui wawancara menunjukkan bahwa setelah pembentukan KTH Mega Buana, selama ini mereka baru dua kali melakukan pertemuan dengan Dinas Kehutanan Setempat. Hal ini menunjukkan bahwa kemampuan aparat pemerintah dalam memfasilitasi masyarakat di dalam dan di sekitar hutan sangat kurang sehingga akan menimbulkan informasi yang bias dan menyimpang kepada masyarakat dalam pengelolaan $\mathrm{HKm}$; (b) Kemampuan sumberdaya manusia pada pengelolaan HKm Pacekke dikategorikan masih kurang optimal. Penyebab dari kurang optimalnya sumberdaya manusia karena kurangnya fasilitas pendampingan, pelatihan, penyuluhan dan kegiatan-kegiatan yang diberikan oleh pihak pemerintah maupun stakeholder lain yang dapat menunjang keberlanjutan pengelolaan $\mathrm{HKm}$ di Pacekke rendahnya kemampuan sumberdaya manusia KTH Mega Buana. Beberapa permasalahan yang ditimbulkan akibat rendahnya kemampuan sumberdaya manusia antara lain kemungkinan terjadi miskomunikasi dan disinformasi, sulit menerima aspirasi/saran dan pengawasan kurang efektif.

5. Sosial Ekonomi, terdapat tiga isu yang berkaitan dengan pemberdayaan masyarakat di dalam dan sekitar hutan yaitu: (a) Hasil wawancara dapat diketahui bahwa masyarakat Desa Pacekke saat ini memiliki pendapatan yang rendah dalam memanfaatkan $\mathrm{HKm}$ sehingga masyarakat cenderung semakin miskin. Semakin miskinnya masyarakat sekitar hutan maka peluang usaha/nilai tambah dari hasil hutan yang diperoleh tidak menjanjikan untuk memenuhi kehidupan; (b) Modal dan infrastruktur ekonomi menurut Wibowo (2016) perlu diprioritaskan karena memiliki kontribusi yang besar terhadap perekonomian masyarakat. Masyarakat Desa Pacekke saat ini kurang termotivasi untuk berwirausaha karena masyarakat kekurangan modal untuk memanfaat hasil hutan dan mereka berpikir belum jelasnya lokasi pemasaran produk yang mereka hasilkan; (c) Jejaring informasi sangat penting untuk menghilangkan keraguan dalam pengelolaan $\mathrm{HKm}$ di Pacekke. Kendala yang terjadi saat ini masyarakat KTH Mega Buana yang mengikuti kegiatan pelatihan oleh Dinas Kehutanan Kabupaten Barru, terkadang hanya langsung menerima informasi yang diberikan tanpa memberikan respon balik. Sehingga masyarakat akan menjadi latah dan mudah dihasut oleh pihak lain. Padahal semestinya masyarakat menjadi tokoh kunci dan paham dengan kondisi sumberdaya hutan yang berada disekitarnya.

\subsection{Skenario Rancangan Program Pemberdayaan Masyarakat}

Kelima isu yang berakar pada kebutuhan peningkatan kapasitas masyarakat Desa Pacekke kemudian dibuat skenario rancangan program pemberdayaan masyarakat secara makro. Skenario program tersebut lebih detail dijelaskan sebagai berikut:

\subsubsection{Kebijakan}

Rancangan kebijakan pemberdayaan masyarakat yang transparan, partisipatif, konsisten dan tepat sasaran diuraikan sebagai berikut:

\subsubsection{Kebijakan Transparan}

Salah satu aspek penting dalam implementasi kebijakan dalam pengelolaan kehutanan menurut Mustafa (2015) adalah adanya asas transparansi atau keterbukaan. Prasyarat ini adalah mutlak mengingat dalam demokrasi saat ini masyarakat yang tinggal di dalam dan sekitar HKm Pacekke berhak mengetahui secara lebih spesifik mengenai konsep dan penerapan kebijakan yang layak dapat segera diwujudkan dan sekaligus memberi manfaat yang sebesar-besaranya bagi kehidupan masyarakat itu sendiri.Seperti kebijakan keterbukaan informasi, maka kini pemerintah maupun stakeholder terkait yang memiliki kepentingan terhadap pengelolaan HKm Desa Pacekke harus memberikan akses informasi seluas-luasnya kepada masyarakat baik melalui media koran, televisi, radio, papan informasi maupun pertemuan rutin yang bersifat nonformal dalam menuju tata kelola hutan yang lestari dan berkelanjutan. 


\subsubsection{Kebijakan Partisipatif}

Partisipasi masyarakat Desa Pacekke dalam setiap program pemberdayaan mutlak diperlukan, tanpa adanya partisipasi masyarakat maka program tersebut hanya objek semata. Rahadian (2011) juga mengemukakan bahwa untuk mendukung hal tersebut harus dibangun suatu deklarasi agar masyarakat turut berpartisipasi dalam kehidupan kolektif.

\subsubsection{Kebijakan Konsisten dan Tepat Sasaran}

Pedoman kebijakan harus jelas sehingga semua anggota KTH Mega Buana, pemerintah dan stakeholder terkait sebagai pelaksana kebijakan tersebut memiliki persepsi yang sama mengenai kebijakan pada pengelolaan HKm Pacekke agar dapat dilaksanakan dengan baik. Kebijakan yang tidak tepat sasaran perlu penanggulangan yang komprehensif karena kebijakan yang baik adalah kebijakan yang selalu mementingkan kepentingan sasaran kebijakan bukan kepentingan para pembuat kebijakan seperti peningkatan akses pelayanan kebutuhan dasar, kesehatan, pendidikan dan pangan kepada masyarakat sekitar HKm Pacekke.

\subsubsection{Kelembagaan}

Rancangan peningkatan kapasitas kelembagaan berbasis kemitraan pada KTH Mega Buana yang dibutuhkan agar tercapainya pengelolaan $\mathrm{HKm}$ yang berkelanjutan yaitu :

\subsubsection{Rencana Pemahaman Kelembagaan dan Pengembangan Administrasi terhadap KTH Mega Buana}

Hal utama yang perlu dilakukan dalam kelembagaan KTH Mega Buana yaitu adanya rancangan pembentukan struktur kepengurusan dan mengetahui masing-masing peran dan fungsinya. Selanjutnya yang perlu dilakukan yaitu melengkapi kebutuhan administrasi KTH lainnya. Kelengkapan administrasi KTH selain struktur kepengurusan yaitu seperti adanya buku tamu, buku kas, buku notulen rapat, AD/ART dan sebaiknya KTH Mega Buana mempunyai lemari tersendiri untuk menyimpan arsip dan buku-buku perpustakaan yang mendukung pengelolaan HKm Pacekke.

\subsubsection{Rencana Studi Banding}

Rencana kegiatan studi banding pada KTH Mega Buana merupakan upaya untuk menambah wawasan dan pengetahuan dalam berusaha bertani modern dan berwawasan lingkungan yang baik. Selain itu dengan adanya studi banding maka anggota KTH Mega Buana akan mendapatkan berbagai macam informasi mulai dari konsep kehutanan berkelanjutan, peran kehutanan hingga persoalan yang dihadapi anggota KTH pada umumnya.

\subsubsection{Rencana Pengembangan Program Koperasi}

Umumnya masyarakat Desa Pacekke memiliki ciri-ciri kegotongroyongan yang kental, saling membantu satu sama lainnya dan solidaritas yang tinggi. Berdasarkan ciri-ciri tersebut maka satu-satunya badan usaha yang sesuai dengan jiwa masyarakat pedesaan yaitu Koperasi Unit Desa (KUD).

Melalui KUD inilah masyarakat Desa Pacekke mampu melakukan aktivitas simpan pinjam, pemasaran, layanan jasa, kegiatan komsumsi maupun produksi hasil usaha dari hutan. KUD dapat diibaratkan sebagai wadah organisasi ekonomi sosial kemasyarakatan.

\subsubsection{Sumberdaya Hutan}

Selaku aktor utama dalam kegiatan pemberdayaan masyarakat, masyarakat yang tinggal di dalam dan sekitar HKm Pacekke perlu rancangan sumberdaya hutan yang berbasis masyarakat diuraikan sebagai berikut : 


\subsubsection{Rencana Budidaya Hasil Hutan}

Berikut ini beberapa rancangan budidaya yang dapat dilakukan pada HKm Desa Pacekke :

\subsection{Budidaya Tanaman Obat}

Apabila masyarakat Desa Pacekke melakukan budidaya tanaman obat pada lokasi HKm maka akan dapat memperbaiki status gizi khusunya bagi anak-anak, meningkatkan sarana pendapatan dengan menjual hasil tanaman obat, serta sarana untuk pelestarian hutan.

\subsection{Budidaya Tanaman Hias}

Membudidayakan tanaman hias maka masyarakat Desa Pacekke akan memperoleh manfaat dari segi ekonomi yang dapat meningkatkan pendapatan masyarakat dan dari segi ekologi dapat meningkatkan nilai keindahan lingkungan, kesuburan hara terjaga, menyediakan udara bersih serta menjaga terjadinya erosi.

\subsection{Budidaya Jenis Tanaman Serbaguna (Multi Purpose Tree Species)}

Upaya menanam jenis tanaman serbaguna juga dapat memberikan hasil berupa getah, buah, daun, bunga, serat, pakan ternak dan sebagainya. Jenis tanaman MPTS yang dirancang untuk dibudidayakan pada pengelolaan HKm Desa Pacekke dapat dilihat pada Tabel 1.

Tabel 1. Jenis Tanaman MPTS yang direkomendasikan untuk dibudidayakan

\begin{tabular}{cll}
\hline No & \multicolumn{1}{c}{ Nama Daerah } & Nama Ilmiah \\
\hline 1 & Matoa & Pometia pinata \\
\hline 2 & Sukun & Artocarpus altilis \\
\hline 3 & Aren & Arenga pinata \\
\hline 4 & Jambe Mente & Anacardium ocidentale \\
\hline
\end{tabular}

\subsection{Budidaya Lebah}

Usaha untuk membudidayakan lebah merupakan salah satu usaha potensial untuk dikembangkan sebab di lokasi HKm Desa Pacekke memiliki Petak Areal Kerja (PAK) cukup luas yakni sekitar 150 ha. Bila $\mathrm{HKm}$ tersebut dimanfaatkan pemeliharaan lemah madu secara intensif maka Desa Pacekke dapat menjadi salah satu desa pemasok madu di Sulawesi Selatan.Pemeliharaan lebah juga tidak hanya menguntungkan secara ekonomis, tetapi juga mampu menciptakan lapangan kerja sekaligus menunjang produktivitas $\mathrm{HKm}$ di desa tersebut.

\subsubsection{Rencana Pengembangan Agroforestry}

Perencanaan di bidang Agroforestry menjadi salah satu solusi dalam rangka mengatur pola kegiatan masyarakat dalam HKm Desa Pacekke yang termasuk hutan lindung. Sejalan dengan hal tersebut hasil penelitian yang dilakukan oleh Wijayanto dan Hartoyo (2015) menyimpulkan bahwa masyarakat yang mengembangkan Agroforestry telah menerapkan biodiversitas dalam sistem penggunaan lahan, dan juga menghasilkan produk-produk unggulan yang bernilai ekspor. 


\subsubsection{Rencana Pemungutan Hasil Hutan Bukan Kayu (HHBK)}

Pengelolaan HKm Pacekke hanya perlu diarahkan sebagai penghasil HHBK yang dapat membuka kegiatan pemberdayaan dan penghasilan bagi masyarakat dengan memperhatikan nilai ekologis.HKm Desa Pacekke termasuk hutan lindung maka masyarakat hanya dapat memungut HHBK. Saat ini masyarakat hanya memungut HHBK dari HKm Pacekke berupa nira aren berkisar 100 liter/bulan dan madu \pm 70 liter/bulan.

\subsubsection{Rencana Perlindungan dan Rehabilitasi Hutan}

Rencana perlindungan dan rehabilitasi hutan merupakan salah satu upaya demi terjaminnya produktivitas, biodiversitas, vitalitas dan ruang tumbuh dalam pengelolaan HKm Desa Pacekke.

\subsubsection{Sumberdaya Manusia}

Rancangan pemberdayaan masyarakat yang sesuai pada peningkatan kemampuan sumberdaya manusia adalah sebagai berikut:

\subsubsection{Rencana Pelatihan Pembibitan dan Budidaya}

Keinginan masyarakat Desa Pacekke untuk membudidayakan beberapa jenis tanaman sebagai upaya rehabilitasi hutan dibatasi oleh ketidakmampuan mereka untuk memperoleh bibit yang unggul. Oleh karena itu masyarakat cenderung menanam tanaman tersebut hanya dari biji atau benih yang tidak jelas asal usulnya yang mengakibatkan tanaman akan memerlukan waktu lebih panjang untuk berproduksi. Bertolak pada masalah tersebut, maka dipandang perlu diselenggarakan pelatihan pembibitan dan pembudidayaan tanaman untuk meningkatkan kemampuan pengetahuan dan keterampilan masyarakat.

\subsubsection{Rencana Pelatihan Pemanenan dan Pasca Pemanenan}

Penanganan panen dan pasca panen yang tidak tepat atau tidak memenuhi syarat mengakibatkan mutu yang rendah dan kehilangan hasil sehingga produksi akan berkurang. Oleh karena itu perlu diadakan pelatihan terkait praktek pemanenan agar masyarakat memiliki wawasan tentang produksi dan mutu hasil hutan.

\subsubsection{Rencana Pelatihan Keterampilan dan Manajemen Usaha}

Menjalankan usaha dari hasil pengelolaan HKm Desa Pacekke kemungkinan melibatkan pekerjaanpekerjaan rutin yang masyarakat tidak sukai. Hal ini yang menjadi tantangan bagi aparat pemerintah untuk memberikan pelatihan agar masyarakat Desa Pacekke memahami strategi pengelolaan pemasaran usaha dari hasil hutan, pengelolaan produksi pada usaha hasil hutan, serta pengelolaan permodalan dan keuangan usaha hasil hutan.

\subsubsection{Sosial Ekonomi}

Rancangan peningkatan akses dan penguatan kapasitas sosial ekonomi yang dibutuhkan yaitu:

\subsubsection{Rencana Pengembangan Usaha Hasil Hutan Bukan Kayu (HHBK)}

Rencana ini ditujukan dalam rangka pengelolaan HHBK untuk kegiatan usaha sehingga dapat menopang perekonomian masyarakat Desa Pacekke. Rencana ini perlu memperhatikan aspek-aspek penting yang dapat menjadi tantangan terutama dalam mengembangkan usaha HHBK. Mokhamad dan Hartono (2011) menyebutkan bahwa tantangan pengembangan usaha mengcakup aspek yang luas antara lain: (a). Peningkatan Kualitas SDM dalam hal kemampuan manajemen, (b). Organisasi dan teknologi, (c). Akses yang lebih luas terhadap permodalan, serta (d). Informasi pasar yang transparan. 


\subsubsection{Rencana Pengembangan Usaha Pemanfaatan Jasa Lingkungan}

Rencana ini dalam rangka memanfaatkan jasa lingkungan yang tersedia di HKm Desa Pacekke sehingga pemanfaatan hutan tidak hanya sebatas pemungutan HHBK saja. Pengembangan usaha jasa lingkungan antara lain rencana pengembangan usaha perdagangan karbon (carbon tarding). Dengan demikian rencana pemanfaatan jasa lingkungan seperti ini mempunyai peluang yang cukup menarik bagi masyarakat Desa Pacekke agar percaya bahwa upaya perlindungan hutan akan sulit dilakukan jika manfaat terhadap lingkungan tersebut tidak dinilai secara layak dengan uang atau melalui sistem pembayaran.

\section{KESIMPULAN}

1. Kebutuhan peningkatan kapasitas setelah diidentifikasi melalui lima aspek menunjukkan bahwa kondisi masyarakat Desa Pacekke saat ini memiliki tingkat ketergantungan yang tinggi terhadap program pemerintah dan pihak lainnya; lemahnya akses masyarakat terhadap modal, pasar dan iptek sehingga menyebabkan posisi tawar masyarakat dalam kemitraan rendah; kerusakan hutan akan semakin meningkat karena masyarakat kurang terlibat dalam pengelolaan hutan; lemahnya kemampuan aparat pemerintah sebagai fasilitator pemberdayaan sehingga kemampuan sumberdaya manusia kurang optimal; serta masyarakat kurang termotivasi untuk berwirausaha karena kurangnya modal dan infrastruktur ekonomi yang tersedia sehingga pendapatan masyarakat masih tergolong rendah.

2. Penyusunan rancangan pemberdayaan masyarakat Desa Pacekke yang sesuai kondisi saat ini yaitu antara lain rancangan kebijakan pemberdayaan masyarakat yang transparan, partisipatif, konsisten dan tepat sasaran; rancangan peningkatan kapasitas kelembagaan berbasis kemitraan; rancangan sumberdaya hutan yang berbasis masyarakat; rancangan pelatihan peningkatan kapasitas dan kompetensi sumberdaya manusia oleh aparat pemerintah; serta rancangan peningkatan akses dan penguatan sosial ekonomi masyarakat.

\section{DAFTAR PUSTAKA}

Harlen, S. 2010. Efektivitas Hutan Kemasyarakatan Sebagai Wujud Kolaborasi Pengelolaan Hutan. Skripsi Fakultas Kehutanan Institut Pertanian Bogor. Bogor.

Kementrian Kehutanan. 2007. Lampiran Peraturan Menteri Kehutanan No. P6/Menhut-II/2007 tentang Rencana Makro Pemberdayaan Masyarakat di dalam dan Sekitar Hutan. Jakarta.

Mokhamad, T. dan Hartono. 2011. Model Pengembangan Usaha Kecil Menengah Berbasis Potensi Ekonomi Masyarakat. Jurnal STIE Widya Gama Lumajang. Volume 1 (1).

Mustafa, R. 2015. Transparansi, Syarat Mutlak Kebijakan Publik. Kompasiana.

Noor, M. 2011. Pemberdayaan Masyarakat. Jurnal IImiah CIVIS Volume 1 (2). Semarang.

Purnomo, D. 2013. Modal Sosial dan Pemberdayaan Masyarakat Nelayan. Jurnal Fakultas Ilmu Sosial dan IImu Politik Universitas Hasanuddin. Makassar.

Rahadian, A.P. 2011. Analisis Implementasi Kebijakan tentang Keterbukaan Informasi Publik Studi Kasus pada Kementrian Pertanian. STIAMI. Jakarta Pusat.

Wijayanto, N. dan A.P.P. Hartoyo. 2015. Biodiversitas Berbasiskan Agroforestry. Jurnal Fakultas Kehutanan Institut Pertanian Bogor Volume 1 (2). 